\title{
Focused Arterial Anastomotic Assessment in a Novel Univariate Design of a Vertical Rectus Abdominis Muscle Flap in a Pig Model
}

\author{
Claudia Fischlin, MD ${ }^{1} \quad$ Zacharia Mbaidjol, MD ${ }^{1} \quad$ Radu Olariu, MD ${ }^{1}$ Mihai Constantinescu, MD \\ Jonathan Leckenby, MBBS ${ }^{1}$ \\ ${ }^{1}$ Department of Plastic and Reconstructive Surgery, Inselspital, \\ Bern University Hospital, University of Bern, Bern, Switzerland \\ J Reconstr Microsurg Open 2017;2:e52-e57. \begin{abstract}
of Plastic and Reconstructive Surgery, Inselspital, Bern University Hospital, University of Bern, Bern 3010, Switzerland (e-mail: joleckenby@gmail.com).
\end{abstract} \\ Address for correspondence Jonathan Leckenby, MBBS, Department
}

\begin{abstract}
Background Microsurgical anastomosis is the basis for free tissue transfer. The goal of this study was to create an animal model that mimics free tissue transfer but would focus on the arterial anastomotic assessment alone, without additional bias of a venous anastomosis.

Methods A vertical rectus abdominis musculocutaneous (VRAM) flap based on the left deep superior epigastric artery (DSEA) was raised in six large white pigs. The right DSEA was raised and used as the donor vessel. An arterial end-to-end microsurgical anastomosis was then performed between the right and the left SEA artery. The lateral deep epigastric vein (DIEV) was left intact to drain the flap. Perfusion of the flap was confirmed clinically by laser Doppler and by flowmetry.

Results One flap failure was observed in this study that occurred on postoperative day (POD) 5 as a consequence of venous occlusion due to hematoma. There was a significant initial drop in arterial flow across the anastomosis in comparison to preanastomotic flow measurements $(p<0.05)$; however, this was normalized by the seventh POD $(p>0.05)$. Flow measurements in the vein significantly increased after the arterial anastomosis was completed and the seventh POD $(p<0.05)$. Laser

\section{Keywords}

- microsurgery

- anastomosis

- free flap

- animal model Doppler assessment demonstrated adequate tissue perfusion of the skin island flap. Conclusion This modified VRAM flap is a viable procedure to simulate a free flap transfer and assess the arterial anastomosis alone, while maintaining the flap's innate venous drainage. This method can allow the investigation of new arterial anastomosis techniques and devices.
\end{abstract}

Since the description of the first microsurgical free tissue transfer in humans by Takahashi in $1964,^{1}$ many different types of free tissue transfer have been described. Much attention has been recently paid to perforator flaps ${ }^{2}$ and alternative surgical techniques to raising such flaps ${ }^{3}$; however, there has not been much development in the anastomosis technique.

Many different approaches to anastomosis techniques have been described. Though the gold standard for an arterial anastomosis is to perform interrupted sutures of the front and back wall, ${ }^{4}$ there are more options when addressing the venous anastomosis with the relatively recent introduction of venous couplers. ${ }^{5,6}$ Another variable to consider is the type of anastomosis and whether this is performed end to end, end to side, or even side to side. ${ }^{7-10}$

The causes of flap failure are diverse but can be broadly separated into inflow problems, outflow problems, and received

February 15, 2017

accepted after revision

March 30, 2017
DOI https://doi.org/

$10.1055 / \mathrm{s}-0037-1602817$

ISSN 2377-0813.
Copyright $\odot 2017$ by Thieme Medical

Publishers, Inc., 333 Seventh Avenue, New York, NY 10001, USA. Tel: +1(212) 584-4662.
License terms

(요 $\Theta \circledast$ 
intrinsic flap problems. Most commonly the cause is related to problems arising from the venous anastomosis, ${ }^{11-13}$ primarily due to the formation of thrombosis or the anatomical positioning of the flap causing kinking of the vein and therefore disrupting the outflow. Arterial problems are typically attributed to surgical technique, with accidental misplacement of a suture or "catching" the posterior wall being the most common cause. ${ }^{14}$

Animal models play an important role in the development of new surgical techniques. Though the benefits are clear, the anatomy is not always similar so the usefulness is limited to either technical development or principal-based surgery. When developing an experimental model to evaluate an anastomosis technique, the flap must be designed to behave like a free flap. Raising a free flap and placing it back in its original position may be insufficient; the vascular pedicle has been shown to retract, and thus when attempting an anastomosis, it is likely that this will be under additional tension and therefore suboptimal. ${ }^{15-17}$ When developing a new technique for arterial anastomosis, it would be ideal if all other parameters could be controlled; however, this is seldom possible.

The aim of this study is to describe a modification of the vertical rectus abdominis muscle (VRAM) flap to overcome the problems associated with performing a venous anastomosis in a porcine model.

\section{Materials and Methods}

\section{Anatomy}

The anatomy of the anterior abdominal wall in a pig is grossly similar to the human; however, there are some subtle but important differences in the vascular supply. In humans, the VRAM flap can be based either on deep superior epigastric artery (DSEA) and vein (DSEV) or the deep inferior epigastric artery (DIEA) and vein (DIEV), as it is classified as a type III flap. ${ }^{18}$ In the pig, the superior epigastric vessels are dominant and of a larger caliber when compared with the inferior epigastric vessels and the flap cannot be reliably based on the inferior vessels, essentially behaving as a type II flap. Therefore, it is prudent to select the superior epigastrics when considering the VRAM as a flap model in pigs.

At the level of the umbilicus, the DIEV divides into two branches in the pig. The larger branch is given off laterally and is accompanied by a small-caliber artery. The smaller branch continues caudally and forms a venous plexus just inferior to the umbilicus before emerging as the DIEV.

\section{Animals}

Six female adult white wild-type pigs $(42.3 \pm 5.7 \mathrm{~kg})$ were used in this study. All animal experimentations were performed after approval from the Animal Care Committee of the Canton of Bern, Switzerland BE137/14 and in agreement with the guidelines for the care and use of experimental animals of the National Institutes of Health. The animals were transported 4 days prior to surgery from the breeder to the Veterinary Hospital in Bern where they underwent a physical examination by the veterinary from the Experimental Research Unit (ESI, Insel Hospital, Bern, Switzerland).
They were housed in a controlled environment, fed a standard diet, and given an unrestricted access to water until 12 hours prior to surgery. All surgical procedures were performed under general anesthesia. The animals were sedated intramuscularly with $20 \mathrm{mg} / \mathrm{kg}$ ketamine (Vetoquiol AG, Ittigen, Switzerland) and $2 \mathrm{mg} / \mathrm{kg}$ xylazine (Vetoquiol AG, Ittigen, Switzerland), followed by tracheal intubation 10 minutes later and intravenous administration of $0.5 \mathrm{mg} / \mathrm{kg}$ midazolam (University Hospital Bern, Switzerland) and 0.05 $\mathrm{mg} / \mathrm{kg}$ atropine (University Hospital Bern, Switzerland). The animals were closely monitored during surgery and general anesthesia was maintained with halothane and $79 \%$ nitrous oxide in oxygen. Ventilation was maintained with oxygen/air 1:3 and isoflurane (University Hospital, Bern, Switzerland) 1 to $1.5 \%$ vol. The animals were laid in a supine position and prepped and draped in a sterile manner. The same team of surgeons performed all the operations.

\section{Operative Procedure}

Throughout the procedure, the animals were positioned in the supine position and mechanically ventilated $\left(\mathrm{O}_{2} /\right.$ air $1: 3$, isoflurane $1-1.5 \mathrm{vol} \%)$, and no paralyzing agents were administered.

A right paramedian incision was made extending from the junction of the costal margin and xiphoid process, down to approximately $5 \mathrm{~cm}$ inferior to the umbilicus (-Fig. 1). A 5$\times 10-\mathrm{cm}$ skin island incorporating two nipples was designed to allow for clinical flap observation. The external and internal oblique muscles were divided and the anterior rectus sheath was exposed. The skin flaps, including the external and internal oblique muscles, were elevated off the rectus sheath. The sheath was opened to expose the rectus

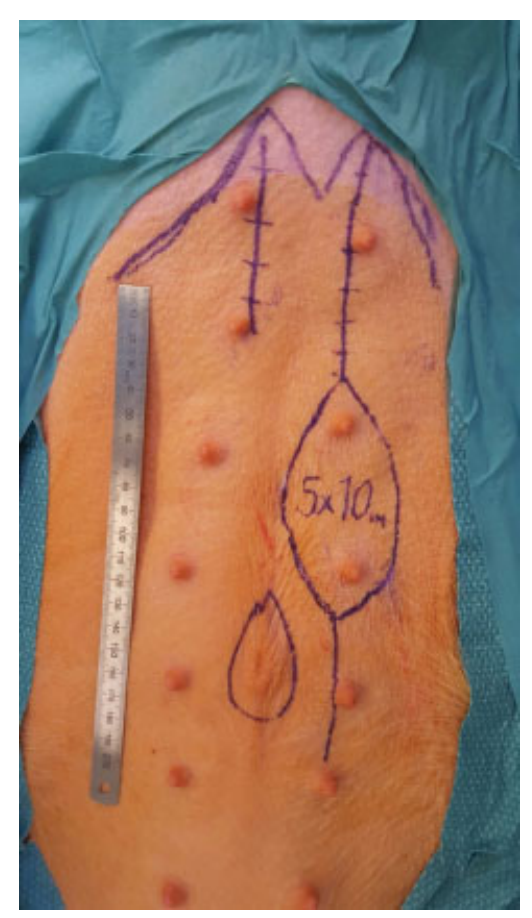

Fig. 1 Preoperative skin markings demonstrating the flap design and the contralateral skin incision for the exposure of the contralateral superior epigastric vessels. 


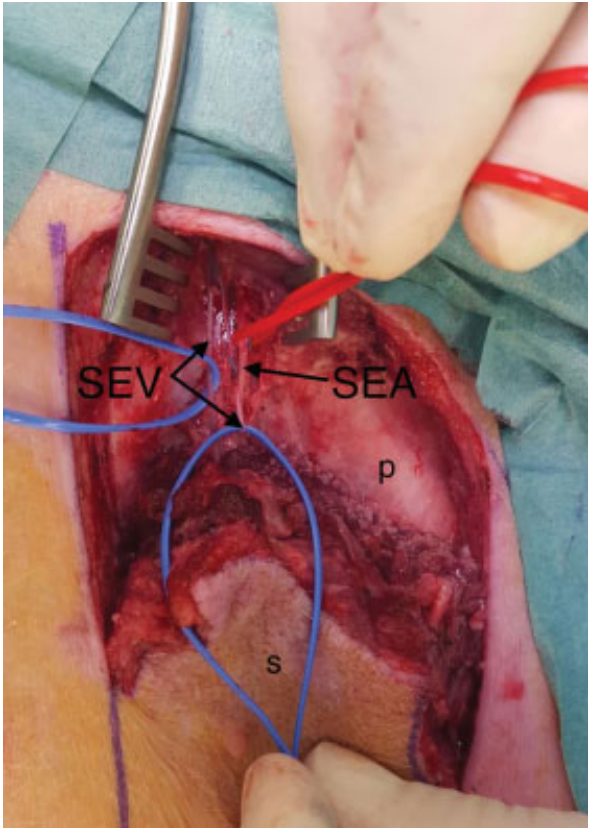

Fig. 2 Isolation of the deep superior epigastric (DSE) vessels. The top of the image is cranial. The donor artery (labeled superficial epigastric artery [SEA]) was always accompanied by two vena comitantes (labeled superficial epigastric vein [SEV]). The two veins were ligated and the artery was divided and prepared for transfer to the contralateral DSEA and prepared for anastomosis. p, posterior rectus sheath; s, skin island.

abdominis muscle. This was released from its costal margin origin to reveal the deep superior epigastric vessels emerging from the notch between the costal margin and xiphoid process; the artery was always accompanied by two veins (-Fig. 2). The deep superior epigastric vessels were ligated using medium Ligaclips (Ethicon, Norderstedt, Germany). The muscle was dissected in a proximal to distal fashion, ligating the medial and lateral rows of perforators given off at each of the multiple tendinous intersections. The vascular pedicle was observed and protected at all times during flap raising. The muscle was raised distally to the level of the umbilicus. At this level the DIEV was seen to branch into the major lateral branch and minor inferior branch. The artery was the converse, with the major branch continuing inferiorly. At this level, the muscle was transected taking care not to injure the inferior vasculature. The lateral vein was skeletonized and preserved ( - Fig. 3), whereas the inferior vein was ligated along with both DIEAs.

A second incision on the contralateral side was made extending inferiorly from the right xiphoid notch for $10 \mathrm{~cm}$ (-Fig. 1). The external and internal oblique muscles, anterior rectus sheath, and rectus abdominis were split to expose the right deep superior epigastric vessels. The vessels were skeletonized and followed inferiorly for 10 to $12 \mathrm{~cm}$, at which level the vessels were ligated using Ligaclips (Ethicon). A subcutaneous tunnel was developed inferior to the xiphoid process and the right DSEA was passed to the left side.

The left DSEA was prepared for microsurgical anastomosis to the right DSEA. An end-to-end microsurgical anastomosis

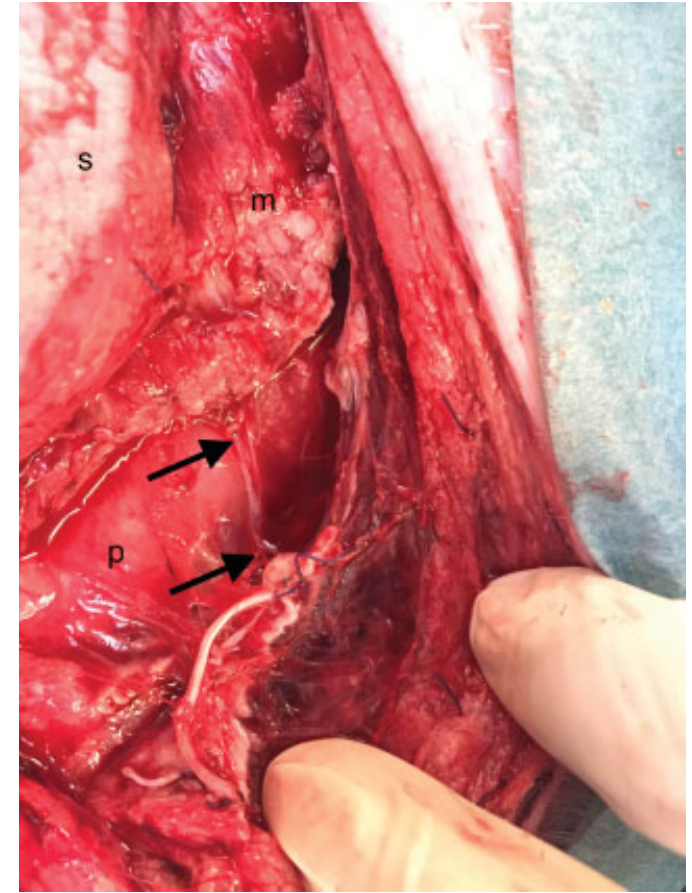

Fig. 3 The lateral deep inferior epigastric vein (DIEV) (marked between arrows) was prepared and left intact while all other venous drainage of the flap was occluded. The top of the image is cranial for orientation. Adequate flap venous drainage was confirmed clinically and with Doppler flowmetry. $\mathrm{m}$, divided inferior edge of rectus abdominis muscle; $p$, posterior rectus sheath; s, skin island.

was performed between the two arteries using 10-0 Nylon, and 5,000 $\mathrm{U}$ heparin was given just prior to the removal of the vessel clamps. Flow across the anastomosis was confirmed by performing Acland's test and by Doppler flowmetry. Attention was then turned to the DIEV, flow was confirmed similarly, and clinically the skin island was observed to be well perfused.

After hemostasis, the rectus sheath was closed with 1-0 Vicryl, the muscle was inset with 3-0 Vicryl, and layered closure was accomplished using 3-0 Vicryl. The skin was closed intracutaneously with 3-0 Monocryl. The incisions were covered with OpSite spray (Smith \& Nephew, Aarau, Switzerland).

\section{Postoperative Care}

After surgery, the animals received prophylactic antibiotic therapy (Baytril, $2 \mathrm{~mL}$ IM. daily) and postoperative analgesia via a morphine patch (Durogesic, $25 \mu \mathrm{g} / \mathrm{h}$ ). Free access to food and water was granted and animals were allowed to move freely in their cage. Thrombosis prophylaxis was performed daily using low-molecular-weight heparin (Clexane, $0.1 \mathrm{mLSC}$ ). Monitoring of animal well-being and of the flap was performed 3 hours postoperatively and then every 8 hours for 2 days.

On the seventh postoperative day (POD), the animal was anaesthetized in the manner previously described. Clinical observation of the skin island was made (-Fig. 4) and perfusion was also assessed using laser Doppler for confirmation ( - Fig. 5). The previous incision was opened and the arterial anastomosis was exposed. Flow rates were measured using Doppler flowmetry of both the DSEA and DIEV at the 


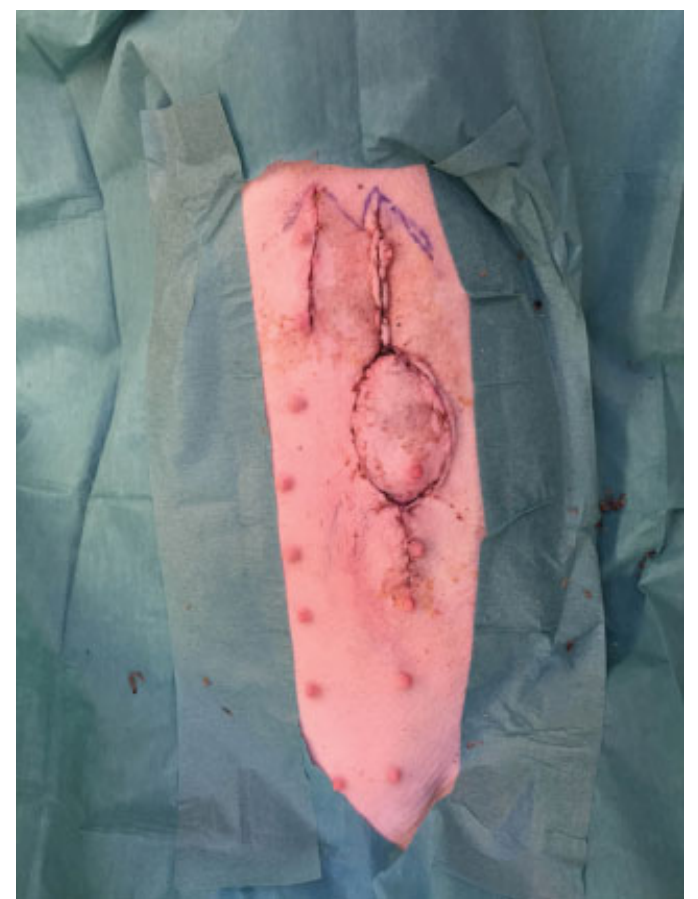

Fig. 4 The clinical appearance of the skin island 7 days postoperatively.

same distances measured previously. Following data acquisition, euthanasia was performed by injecting $10 \mathrm{~mL}$ of intravenous potassium chloride during deep anesthesia.

Statistical analysis was completed using Prism software (GraphPad Software Inc., San Diego, CA) implementing $t$-tests to compare the groups.

\section{Results}

Anatomic dissections revealed constant anatomy in the chosen animal model with no exception. The xiphoid notch was a constant landmark from where the deep superior epigastric vessels emerged from the chest cavity. The diameter of the DSEA as it emerged from the xiphoid notch was

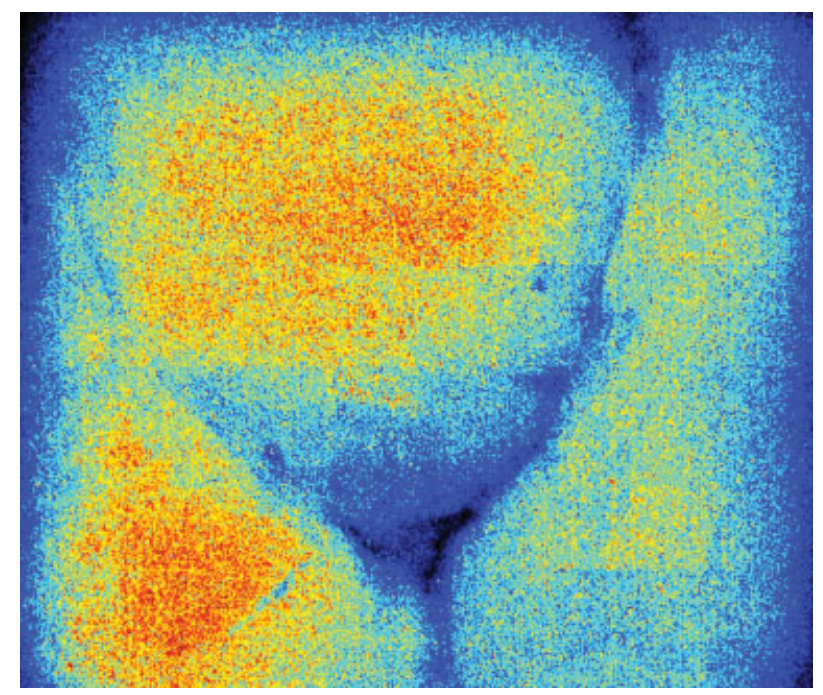

Fig. 5 Laser Doppler confirmation of adequate skin flap perfusion.
$1.2 \mathrm{~mm}$ (standard deviation [SD] $0.17 \mathrm{~mm}$ ) and the DSEV was $0.9 \mathrm{~mm}$ (SD $0.09 \mathrm{~mm}$ ). Ten $\mathrm{cm}$ distal to the xiphoid notch, the DSEA diameter was $0.9 \mathrm{~mm}$ (SD $0.12 \mathrm{~mm}$ ) and the DSEV was $0.8 \mathrm{~mm}$ (SD $0.11 \mathrm{~mm}$ ).

In contrast, the DIEA and DIEV were considerably smaller. At the level of the umbilicus, the diameter of the lateral DIEA was $0.2 \mathrm{~mm}$ (SD $0.09 \mathrm{~mm}$ ) and lateral DIEV was $0.4 \mathrm{~mm}$ (SD $0.12 \mathrm{~mm}$ ), the diameter of the inferior DIEA was $0.5 \mathrm{~mm}$ (SD $0.13 \mathrm{~mm}$ ), and the inferior DIEV was $0.2 \mathrm{~mm}$ (SD $0.08 \mathrm{~mm}$ ).

Flow across the arterial anastomosis was measured with Doppler flowmetry. Measurements were made either side of the anastomosis immediately following anastomosis and at the seventh POD. Prior to anastomosis, flow in the right DSEA (donor artery) $1 \mathrm{~cm}$ proximal to the planned anastomosis was $12.42 \mathrm{~mL} / \mathrm{min}$ (SD 3.23) and the flow in the left DSEA (recipient) $1 \mathrm{~cm}$ distal to the planned anastomosis was 14.36 $\mathrm{mL} / \mathrm{min}$ (SD 6.32). This was not significant different $(p>0.05)$. The flow in the lateral DIEV was measured prior to any arterial ligation and was $1.88 \mathrm{~mL} / \mathrm{min}$ (SD 0.31). Following ligation of all vessels except the lateral DIEV, flow was demonstrated to drop to 0 . Nearly 15 minutes after completion of the arterial anastomosis, the flow in the DSEA $1 \mathrm{~cm}$ proximal to the anastomosis dropped to $5.32 \mathrm{~mL} / \mathrm{min}$ (SD 2.36) and $1 \mathrm{~cm}$ distal to the anastomosis measured 4.42 $\mathrm{mL} / \mathrm{min}$ (SD 1.99). Both results were significantly reduced in comparison to flow measured prior to anastomosis $(p<0.05)$. The lateral DIEV increased to $2.56 \mathrm{~mL} / \mathrm{min}$ (SD 1.08). This was not a significant change.

One flap failure was observed in this study that occurred on POD 5 because of venous occlusion due to hematoma; the flow measurements for this animal were excluded from the results. At the time of the second surgical intervention (POD 7), flow rates were similarly measured. The arterial flow proximal and distal to the anastomosis was $13.56 \mathrm{~mL} / \mathrm{min}$ (SD 1.94) and $12.06 \mathrm{~mL} / \mathrm{min}$ (SD 1.25), respectively, which were not significantly different to the flow rates of either the right or left DSEA prior to anastomosis ( $p>0.05$ ). Regarding the outflow, the DIEV flow rate measured at the same point increased at $7 \mathrm{~mL} /$ min (SD 1.05); this was significantly increased in comparison to venous flow rates prior to anastomosis $(p<0.05)$.

Laser Doppler assessment of the skin island confirmed adequate flap perfusion 45 minutes following the completion of the arterial anastomosis (-Fig. 5). Images demonstrated similar perfusion of the skin island in comparison to surround tissue ( $\mathbf{- F i g . 5}$ ). To confirm that the flap was being perfused by the DSEA, the artery was clamped and the skin island ceased to be perfused when assessed by laser Doppler (-Fig. 6). All flaps were shown to be adequately perfused on the seventh POD.

\section{Discussion}

This study has shown that this modification of the VRAM flap is a viable technique of simulating a free flap while maintaining the flaps innate venous drainage and transferring the arterial supply to the contralateral side. Because there is no requirement for a venous anastomosis in the model, the risk of outflow problems developing is reduced. This allows 


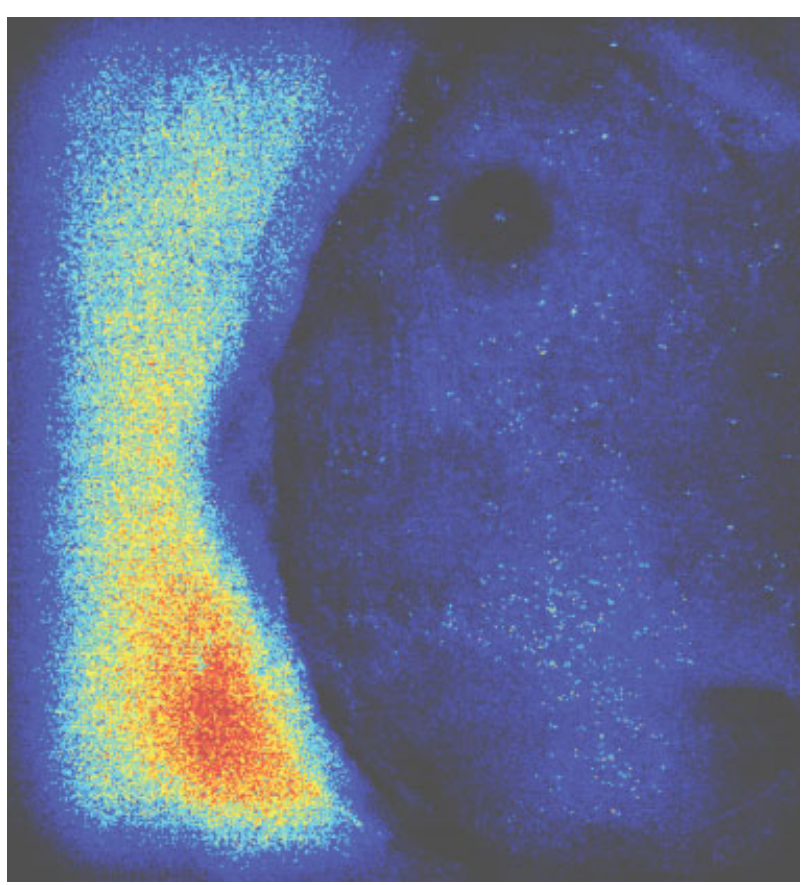

Fig. 6 The laser Doppler appearance of the skin island after arterial occlusion.

arterial anastomosis techniques to be evaluated in a more controlled environment.

By transferring the DSEA to the contralateral side, the arterial anastomosis can be achieved without any tension across the anastomosis. Abundant pedicle length can be achieved by raising the contralateral DSEA distally and $10 \mathrm{~cm}$ appears to be more than adequate for this purpose. This length would also permit other anastomosis techniques to be tried, either with end-to-side or side-to-side methods.

Laser Doppler assessment demonstrated adequate tissue perfusion of the skin island both at the completion of the primary surgery and on the seventh POD. The design of the skin island incorporated two nipples hoping that there would be adequate perforators to supply the skin around these areas; this seemed to be a reliable technique to implement. The flow across the anastomosis significantly fell immediately following completion of the arterial anastomosis $(p<0.05)$. This is likely to be attributed to arterial spasm following surgical manipulation; the fact that flow measurements were restored to preanastomotic levels at the seventh POD supports this explanation $(p>0.05)$. If the artery was temporarily clamped, the perfusion of the skin island was very clearly reduced confirming that the right DSEA was the sole arterial supply of the flap. After 7 days the flow in the DIEV significantly increased $(p<0.05)$, and this may be attributed to the increase venous diversion from the superficial to deep system

The design of this flap potentially opens up new possibilities for anastomosis techniques. New developments in laser anastomosis are being developed, which require a laser probe to be inserted into the artery..$^{19,20}$ This has previously tried through cannulating side branches of the artery; however, this is often difficult due to the size and location of appropriate arteries. With the design of the VRAM flap in this study, it is possible to cannulate the DIEA and pass the probe proximally through the entire length of the flap until it emerges at the divided DSEA.

\section{Conclusion}

This modification of a VRAM flap is a viable model for evaluating arterial anastomosis techniques. The design opens the door to new technologies that can be implemented more easily.

\author{
Funding \\ None. \\ Conflict of Interest \\ None.
}

\section{References}

1 Nakayama K, Yamamoto K, Tamiya T, et al. Experience with free autografts of the bowel with a new venous anastomosis apparatus. Surgery 1964;55:796-802

2 Scaglioni MF, Fakin RM, Giovanoli P, Kuo YR, Kuo PJ. The lower medial thigh perforator (LMTP) flap for lower extremity reconstruction: preliminary results. Microsurgery 2016;36(06): 474-479

3 Hong JP, Choi DH, Suh H, et al. A new plane of elevation: the superficial fascial plane for perforator flap elevation. J Reconstr Microsurg 2014;30(07):491-496

4 Schlechter B, Guyuron B. A comparison of different suture techniques for microvascular anastomosis. Ann Plast Surg 1994;33 (01):28-31

5 Jandali S, Wu LC, Vega SJ, Kovach SJ, Serletti JM. 1000 consecutive venous anastomoses using the microvascular anastomotic coupler in breast reconstruction. Plast Reconstr Surg 2010;125(03): 792-798

6 Barker EV, Enepekides DJ. The utility of microvascular anastomotic devices in head and neck reconstruction. Curr Opin Otolaryngol Head Neck Surg 2008;16(04):331-334

7 Tsai YT, Lin TS. The suitability of end-to-side microvascular anastomosis in free flap transfer for limb reconstruction. Ann Plast Surg 2012;68(02):171-174

8 Miyamoto S, Sakuraba M, Asano T, et al. Optimal technique for microvascular anastomosis of very small vessels: comparative study of three techniques in a rat superficial inferior epigastric arterial flap model. J Plast Reconstr Aesthet Surg 2010;63(07): 1196-1201

9 Miyamoto S, Takushima A, Okazaki M, Ohura N, Momosawa A, Harii K. Comparative study of different combinations of microvascular anastomosis types in a rat vasospasm model: versatility of end-to-side venous anastomosis in free tissue transfer for extremity reconstruction. J Trauma 2009;66(03):831-834

10 Dotson RJ, Bishop AT, Wood MB, Schroeder A. End-to-end versus end-to-side arterial anastomosis patency in microvascular surgery. Microsurgery 1998;18(02):125-128

11 Mirzabeigi MN, Wang T, Kovach SJ, Taylor JA, Serletti JM, Wu LC. Free flap take-back following postoperative microvascular compromise: predicting salvage versus failure. Plast Reconstr Surg 2012;130(03):579-589

12 Yu P, Chang DW, Miller MJ, Reece G, Robb GL. Analysis of 49 cases of flap compromise in 1310 free flaps for head and neck reconstruction. Head Neck 2009;31(01):45-51 
13 Williams JG, French RJ, Lalonde DH. Why do free flap vessels thrombose? Lessons learned from implantable Doppler monitoring. Can J Plast Surg 2004;12(01):23-26

14 Novakovic D, Patel RS, Goldstein DP, Gullane PJ. Salvage of failed free flaps used in head and neck reconstruction. Head Neck Oncol 2009;1:33. Doi: 10.1186/1758-3284-1-33

15 Cardamone L, Valentín A, Eberth JF, Humphrey JD. Origin of axial prestretch and residual stress in arteries. Biomech Model Mechanobiol 2009;8(06):431-446

16 Wilber RG, Shaffer JW, Field GA. The effect of redundancy and tension on microvascular vein grafts. J Hand Surg Am 1984;9(05): $649-652$
17 Topalan M, Bilgin SS, Ip WY, Chow SP. Effect of torsion on microarterial anastomosis patency. Microsurgery 2003;23(01): 56-59

18 Mathes SJ, Nahai F. Classification of the vascular anatomy of muscles: experimental and clinical correlation. Plast Reconstr Surg 1981;67(02):177-187

19 Bregy A, Bogni S, Bernau VJ, et al. Solder doped polycaprolactone scaffold enables reproducible laser tissue soldering. Lasers Surg Med 2008;40(10):716-725

20 Alfieri A, Bregy A, Constantinescu M, et al. Tight contact technique during side-to-side laser tissue soldering of rabbit aortas improves tensile strength. Acta Neurochir Suppl (Wien) 2008;103:87-92 